Original article

\title{
Synthesis of novel $\alpha$-santonin derivatives as potential cytotoxic agents
}

\author{
Francisco F.P. Arantes ${ }^{a}$, Luiz C.A. Barbosa ${ }^{\mathrm{a}, *}$, Célia R.A. Maltha ${ }^{\mathrm{a}}$, Antônio J. Demuner ${ }^{\mathrm{a}}$, \\ Patricia Marçal da Costa ${ }^{b}$, José R.O. Ferreira ${ }^{b}$, Letícia V. Costa-Lotufo ${ }^{b}$, Manoel O. Moraes ${ }^{b}$, \\ Cláudia Pessoa ${ }^{\mathrm{b}}$ \\ ${ }^{a}$ Department of Chemistry, Universidade Federal de Viçosa, Av. P.H. Rolfs, S/N, CEP 36570-000, Viçosa, MG, Brazil \\ ${ }^{\mathrm{b}}$ Department of Physiology and Pharmacology, Federal University of Ceará, Rua Coronel Nunes de Melo, 1127, CEP 60431-970, Fortaleza, CE, Brazil
}

\section{A R T I C L E I N F O}

Article history:

Received 26 May 2010

Received in revised form

29 September 2010

Accepted 1 October 2010

Available online 23 October 2010

\section{Keywords:}

Parishin A synthesis

Sesquiterpene lactones

$\alpha$-methylene- $\gamma$-lactone

Endoperoxide bridge

Cytotoxicity

\begin{abstract}
A B S T R A C T
Ten novel $\alpha$-santonin derivatives have been synthesized as cytotoxic agents. The in vitro antitumor activity of these compounds has been evaluated against cancer cells lines. Structure-activity relationships indicate that $\alpha$-methylene- $\gamma$-lactone and endoperoxide functionalities play important roles in conferring cytotoxicity. The compounds $\mathbf{2}-\mathbf{4}$, possessing the $\alpha$-methylene- $\gamma$-lactone group showed $\mathrm{IC}_{50}$ values between 5.70 and $16.40 \mu \mathrm{M}$. Mixture of isomers 5 and $\mathbf{6}$, with the $\alpha$-methylene- $\gamma$-lactone and endoperoxide functionalities, displayed the greatest activity, with $\mathrm{IC}_{50}$ values between 1.45 and $4.35 \mu \mathrm{M}$. The biological assays conducted with normal cells revealed that the compounds $\mathbf{2}, \mathbf{5}$ and $\mathbf{6}$ are selective against cancer cells lines tested. Bioactive lactones described herein and in our previous report did not cause disruption of the cell membrane in mouse erythrocytes.
\end{abstract}

(C) 2010 Elsevier Masson SAS. All rights reserved.

\section{Introduction}

Sesquiterpene lactones (SQLs) are an important class of natural products found in plants of the Asteraceae family, formed by condensation of three isoprene units and subsequent enzymemediated cyclizations and oxidative transformations which produce either cis- or trans-fused lactones [1]. Several natural and synthetic sesquiterpene lactones have been reported to possess anti-inflamatory, phytotoxic, antiprotozoal and cytotoxic activities [2-9].

These different activities have been ascribed mainly to the $\alpha$ methylene- $\gamma$-lactone and $\alpha, \beta$-unsaturated cyclopentanone functionalities, which are prone to react with suitable nucleophiles, e.g., cysteine thiol groups, in a Michael addition reaction [10-16].

Several studies indicate that the mechanism by which SQLs exert their cytotoxic activities is strongly related to their inhibitory effect on many thiol-containing enzymes, involved in the synthesis and processing of proteins, RNA and DNA [17-19]. In addition, SQLs inhibit the cell growth by inducing apoptosis in many types of cell lines [20,21]. The DNA-fragmentation and apoptosis activity of sesquiterpene lactones is mediated by glutathione depletion of the cells and is related to the binding between $\alpha$-methylene- $\gamma$-lactone groups and thiols [22]. This was also confirmed in a study of

\footnotetext{
* Corresponding author. Tel.: +55 313899 3068; fax: +55 3138993065 .

E-mail address: lcab@ufv.br (L.C.A. Barbosa).
}

arteminolides (another group of sesquiterpenes) where structural changes in the lactone ring changed the activity of these compounds against various cancer cell lines [23]

Another important structural factor related to the bioactivity of SQLs is the presence of an endoperoxide bridge, such as that observed in the structure of artemisinin, well known for its antimalarial and phytotoxic activities [24]. Such activities seem to be related to the generation of reactive oxygen species [25].

In our previous report, we have described the synthesis of $\alpha$ santonin derivatives. Some of which possessing the $\alpha$-methylene- $\gamma$ lactone group in their structure, exerted relatively high cytotoxic activity against cancer cells in vitro [16]. In our ongoing effort to discover novel cytotoxic compounds [16,26-31], we describe herein the preparation of new $\alpha$-santonin derivatives. We also report the evaluation of the cytotoxic effects of these lactones against tumor cells as well as an evaluation of the cell membrane disruption, which may be one mechanism by which bioactive lactones described herein (and in our previous report) [16] exert their cytotoxic activities.

\section{Results and discussion}

\subsection{Synthesis}

The sesquiterpene lactones $\mathbf{2}-\mathbf{6 , 8}$ and $\mathbf{1 1 - 1 4}$ were synthesized by a series of reactions as shown in Scheme 1 . The isolated products 
<smiles>C=C1C(=O)O[C@H]2/C(=C/CC(=O)O)C(=C(C)C)CC[C@H]12</smiles>

(i)<smiles>C=C1C(=O)O[C@H]2C3=C(C)C(=O)C[C@]3(C)[C@@H](O)CC[C@@H]12</smiles>
(iii)<smiles>CC(=O)C[C@H]1C(=O)O[C@H]2C3=C(C)C(=O)C[C@]3(C)[C@@](C)(O)CC[C@@H]12</smiles><smiles>CC(=O)C[C@@H]1C(=O)O[C@H]2[C@@H]1CC[C@]1(C)C3(C)C(=O)C=CC231</smiles><smiles>C=C1C(=O)O[C@H]2C3=CCC(=O)C(C)(C)C3=CC[C@H]12</smiles>

(vi)<smiles>C=C1C(=O)O[C@H]2C3=C[C@H]4O[C@@]3(CCC[C@@]12O)C(C)(C)C4=O</smiles>

(v)<smiles>C=C1C(=O)O[C@H]2C3=C(C)C(=O)C=C[C@]3(C)CC[C@@H]12</smiles>

(iv)<smiles>CC(=O)C[C@H]1C(=O)O[C@H]2C3=C(C)C(=O)C=C[C@]3(C)CC[C@H]12</smiles>

(6)<smiles>C=C1C(=O)O[C@H]2C3=CC4O[C@]3(CC[C@@H]12)C(C)(C)C4=O</smiles>

(11)<smiles>C[C@H]1C(=O)O[C@H]2[C@@H]1CC[C@]1(C)C3(C)C(=O)C=C[C@]231</smiles><smiles>C=C1C(=O)O[C@H]2[C@@H]1CC[C@]1(C)C3(C)C(=O)C=C[C@]231</smiles>
(vii)

[16]

(viii)

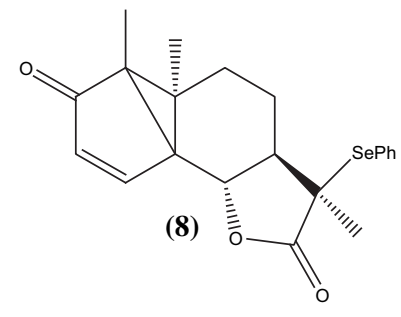

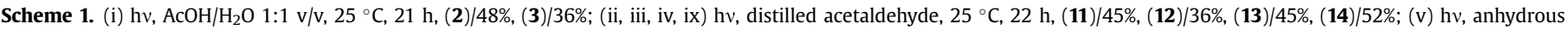

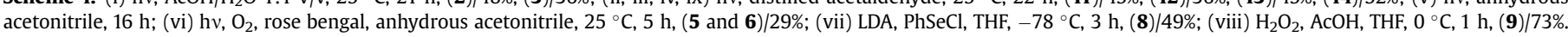

were fully characterized by IR spectroscopy, ${ }^{1} \mathrm{H}$ and ${ }^{13} \mathrm{C}$ NMR spectroscopy, and high resolution mass spectrometry (HRMS).

Irradiation of compound 1, whose synthesis was described in our previous report, with high pressure mercury lamp (125 W), using acetic acid/water mixture $(1: 1 \mathrm{v} / \mathrm{v})$ as solvent in borosilicate reactor, afforded 11,13-dehydroisofotosantonic acid (2) and natural product parishin A (3) in $48 \%$ and $36 \%$ yields, respectively. Parishin
A (3) was first reported from Artemisia tridentata ssp. tridentata f. parishii (Gray) Beetle [32] subsequently from an unidentified Eriocephalus species [33] and, more recently, from Irexis chinensis Nakai (Compositae), known as Siyekucai a perennial plant that grows in various places in China. This plant is used in the folk medicine in China for the treatment of bronchitis, pneumonia, pharyngitis, dysentery, and poisonous indigestion on the basis of its 
antifebrile, antidotal, and analgesic effects [34,35]. Although the isolation of $10 \alpha$-hydroxy-3-oxo-1,7 $\alpha \mathrm{H}, 6 \beta \mathrm{H}$-guaia-4,11-dien-6,12olide (parishin A) has been reported, to our knowledge, there is no report describing its synthesis. The spectroscopic data for the synthesized material were very similar to those of the natural product parishin A reported previously [34]. The infrared spectrum of synthesized compound 3 showed a broad band at $3445 \mathrm{~cm}^{-1}$ associated with $\mathrm{O}-\mathrm{H}$ stretching and two intense bands at 1768 and $1699 \mathrm{~cm}^{-1}$, corresponding to carbonyl stretching of the lactone and ketone, respectively. The ${ }^{1} \mathrm{H}$ NMR spectrum exhibited two singlets arising from methyl groups $\left(\delta_{\mathrm{H}} 0.97 \mathrm{ppm}\right.$ and $\left.\delta_{\mathrm{H}} 1.92 \mathrm{ppm}\right)$, two doublets $\left(\delta_{\mathrm{H}} 5.60\right.$ and $6.30 \mathrm{ppm}, J=3.0 \mathrm{~Hz}$ ) due to the double bond exocyclic, two double doublets related to the $\mathrm{H}$-atoms alpha to the ketone carbonyl, along with characteristic signals with appropriate chemical shifts and coupling constants for the other H-atoms. The ${ }^{13} \mathrm{C}$ NMR spectrum showed a signal $\left(\delta_{\mathrm{C}} 74.66 \mathrm{ppm}\right)$ corresponding to the carbon linked to the hydroxyl group along with others signals which helped to confirm the identity of the synthesized natural product parishin A (3).

The melting point $\left(177.0-178.1^{\circ} \mathrm{C}\right)$ for the synthesized material was slightly lower than those observed for the natural material $\left(185.5-186.5^{\circ} \mathrm{C}\right)$, whereas the optical rotation $\left([\alpha]^{20}{ }_{\mathrm{D}}+72.8^{\circ}\right)$ was almost equal $\left([\alpha]^{20}{ }_{D}+73.2^{\circ}\right)$. According to Chapman and Englert [36], the formation of the acid $\mathbf{2}$ involves the participation of the intermediates $\mathbf{4}$ and $\mathbf{9}$. The guaianolide $\mathbf{3}$, however, is formed by water nucleophilic attack on the carbon C-10 of compound 1 [37].

Photochemical reaction of compound $\mathbf{1}$ in a quartz reactor, using low pressure mercury lamp $(4 \times 15 \mathrm{~W})$ ) as source of ultraviolet radiation and anhydrous acetonitrile as solvent, gave, after $16 \mathrm{~h}$ of reaction, 11,13-dehydromazdasantonin (4) in quantitative yield.

In order to incorporate a suitable endoperoxide bridge at the desired compound, (4) was submitted to photooxygenation reaction in borosilicate reactor, using high pressure mercury lamp $(250 \mathrm{~W})$, radiating in the visible region, acetonitrile as solvent and rose bengal as photosensitizer. This reaction afforded a mixture of isomers (5) and (6) at a ratio of $1: 1.4$, in $29 \%$ yield. The infrared spectrum of mixture of isomers showed two intense bands at $1741 \mathrm{~cm}^{-1}$ and $1789 \mathrm{~cm}^{-1}$, corresponding to carbonyl stretching of the ketone and lactone, respectively. Note that the band associated with stretching of the ketone carbonyl appeared with wave number much higher $\left(1741 \mathrm{~cm}^{-1}\right)$ than that observed for the equivalent band $\left(1661 \mathrm{~cm}^{-1}\right)$ associated with the starting material $(4)$. The ${ }^{1} \mathrm{H}$ and ${ }^{13} \mathrm{C}$ NMR spectra showed all signals in duplicate. The pair of doublets observed at $\delta_{H} 4.65$ and $\delta_{H} 4.72$ in the ${ }^{1} \mathrm{H}$ NMR spectrum and the six signals around $\delta_{C} 80.00$ in the ${ }^{13} \mathrm{C}$ NMR spectrum, along with other signals, assisted in confirming the formation of the isomeric mixture (5) and (6).

The compound 11,13-dehydrolumisantonin (9), which showed relatively high cytotoxic activity against several tumor lines tested, had been synthesized in our previous report with an overall yield of $5 \%$ [16]. We have now developed a new method of synthesis of this compound aiming to improve overall yield. Treatment of lumisantonin (7), whose synthesis was described in our previous report, with lithium diisopropyl amide (LDA), produced in situ, by reaction between diisopropylamine and butyl lithium, followed by capture of the organolithium with phenyl selenium chloride produced the unpublished selenide $\mathbf{8}$ in $49 \%$ yield. Subsequent treatment of the compound $\mathbf{8}$ with hydrogen peroxide gave $\mathbf{9}$ in 30\% overall yield. Due to high overall yield obtained by this method, it becomes more useful the synthesis of $\mathbf{9}$ via lumisantonin (7). This new method was also applied to the compound $10 \alpha$-acetoxy-3-oxo- $1,7 \alpha \mathrm{H}, 6 \beta \mathrm{H}-$ guaia-4,11-dien-6,12-olide (10), which had been synthesized in our previous report with an overall yield of $1 \%$. However, the reaction of formation of the intermediate selenide failed denying access to the next intermediate.
Compounds 1, 2, 3 and $\mathbf{9}$ were submitted to reactions of acetaldehyde photoaddition to the group $\alpha$-methylene- $\gamma$-lactone, producing the compounds 11, 12, 13 and 14 in 45\%, 36\%, 45\% and $52 \%$ yield, respectively. This reaction is the first step of the synthetic route of oxetane lactones [38]. Oxetane ring containing compounds have been reported to display a wide range of biological activities and this structural feature is regarded to be essential for their bioactivity [39]. Thus, the synthesis and further evaluation of the cytotoxicity of oxetane lactones would allow us to assess how the replacement of $\alpha$-methylene- $\gamma$-lactone group by ring oxetane would affect the cytotoxic activity of sesquiterpene lactones. However, due to the structural complexity of the lactones 1, 2, 3 and $\mathbf{9}$, it was not possible to obtain their corresponding oxetane.

The infrared spectra of compounds 11-14 showed a strong absorption around $1717 \mathrm{~cm}^{-1}$ due to $\mathrm{C}=0$ stretching of the acetyl group added. ${ }^{1} \mathrm{H}$ NMR spectra of these compounds exhibited singlet around $\delta_{H} 2.20$, arising from methyl of the acetyl group and two double doublets (around $\delta_{H} 2.60$ and $\delta_{H} 3.00 \mathrm{ppm}$ ) related to methylene group alpha to the ketone carbonyl of the acetyl group. The presence of these signals along other signals assisted in confirming the formation of the compounds 11-14. The $\alpha$-orientation of the aliphatic chain in $\mathrm{C}-11$ was assigned from the value of $J_{7,11}$ $(12.0 \mathrm{~Hz})$ similar to those found for others eudesmanolides and guaianolides with $\mathrm{H}-11 \beta[40,41]$. The proposed stereochemistry was confirmed by NOEDIFF experiment analysis, where it was detected NOE between the irradiated hydrogen H6- $\beta$ and the hydrogen $\mathrm{H} 11$.

\subsection{Cytotoxicity assay}

The cytotoxicity of the sesquiterpene lactones $(\mathbf{2}-\mathbf{6} ; \mathbf{8}$ and 11-14) was assessed against four tumor cell lines, HL-60 (leukemia), SF-295 (central nervous system), HCT-8 (colon) and MDA-MB-435 (melanoma), using a previously described MTT assay [21]. Doxorubicin was used as positive control in this experiment. The $\mathrm{IC}_{50}$ values of these compounds are summarized in Table 1. Compounds 2 and 3, possessing the $\alpha$-methylene- $\gamma$-lactone group, showed high cytotoxicity against HL-60, SF-295 and HCT-8 tumor cells lines, with $\mathrm{IC}_{50}$ values in the range of $5.70-16.40 \mu \mathrm{M}$. Interestingly, these compounds did not exhibit potency against MDAMB-435 tumor cell line ( $\left.\mathrm{IC}_{50}>100 \mu \mathrm{M}\right)$. In the study of Zhang et al. [35], the natural product parishin A (3), isolated from I. chinensis, showed moderate cytotoxic potency against WI-38 (fibroblasts), VA-13 (lung) and HepG2 (human hepatoma) human cancer cell lines, with $\mathrm{IC}_{50}$ of $24.0,22.0$, and $23.0 \mu \mathrm{M}$, respectively.

Compound 4, which also shows the $\alpha$-methylene- $\gamma$-lactone group in its structure, was moderately potent against HL-60 and MDA-MB-435 tumor cells lines, with $\mathrm{IC}_{50}$ of 11.90 and $8.60 \mu \mathrm{M}$, respectively, however, it was inactive against other tumor cells tested $\left(\mathrm{IC}_{50}>100 \mu \mathrm{M}\right)$.

Addition of an endoperoxide bridge at compound 4, giving the mixture of isomers 5 and $\mathbf{6}$, significantly increased the potency against tumor cells lines tested, with $\mathrm{IC}_{50}$ values of $1.45 \mu \mathrm{M}$ (HL-60), $2.54 \mu \mathrm{M}$ (SF-295), $4.35 \mu \mathrm{M}$ (HCT-8) and $3.26 \mu \mathrm{M}$ (MDA-MB-435). Judging by the potency of the compound 4 , the endoperoxide group is an important structural feature for engendering good activity of isomeric mixture of 5 and $\mathbf{6}$. Compound 8 showed IC $_{50}$ of $8.73 \mu \mathrm{M}$ against HL-60 tumor cell line but was unable to significantly inhibit other cells line growths $\left(\mathrm{IC}_{50}>100 \mu \mathrm{M}\right)$.

The cytotoxicity of the compounds $\mathbf{2}$ and $\mathbf{3}$ and isomeric mixture $\mathbf{5}$ and $\mathbf{6}$ were also evaluated against normal cells (PBMC). The compound 2 was less toxic for PBMC, except for MDA-MB-435 cancer cell; these data show that the tumor cells were more sensitive than the normal cells. However compound $\mathbf{3}$ showed similar levels of cytotoxicity towards both tumor and normal cell 
Table 1

Cytotoxic activity $\left(\mathrm{IC}_{50}[\mu \mathrm{M}]\right)$ of lactones derivatives of $\alpha$-santonin.

\begin{tabular}{|c|c|c|c|c|c|c|c|c|c|c|}
\hline \multirow[t]{2}{*}{ Cell lines } & \multicolumn{10}{|l|}{ Lactones } \\
\hline & 2 & 3 & 4 & 5 and 6 & 8 & 11 & 12 & 13 & 14 & Doxorubicin \\
\hline \multicolumn{11}{|l|}{ Tumor cells } \\
\hline HL-60 & $\begin{array}{l}8.70 \\
6.87-11.07\end{array}$ & $\begin{array}{l}5.70 \\
4.56-6.84\end{array}$ & $\begin{array}{l}11.90 \\
8.62-16.41\end{array}$ & $\begin{array}{l}1.45 \\
1.45-1.81\end{array}$ & $\begin{array}{l}8.73 \\
6.98-10.97\end{array}$ & $>100$ & $>100$ & $>100$ & $>100$ & $\begin{array}{l}0.04 \\
0.02-0.04\end{array}$ \\
\hline SF-295 & $\begin{array}{l}16.40 \\
14.49-18.69\end{array}$ & $\begin{array}{l}10.30 \\
9.16-11.45\end{array}$ & $>100$ & $\begin{array}{l}2.54 \\
1.81-2.90\end{array}$ & $>100$ & $>100$ & $>100$ & $>100$ & $>100$ & $\begin{array}{l}0.48 \\
0.40-0.52\end{array}$ \\
\hline HCT-8 & $\begin{array}{l}12.20 \\
10.68-14.11\end{array}$ & $\begin{array}{l}8.30 \\
6.41-10.94\end{array}$ & $>100$ & $\begin{array}{l}4.35 \\
1.45-12.33\end{array}$ & $>100$ & $>100$ & $>100$ & $>100$ & $>100$ & $\begin{array}{l}0.02 \\
0.02-0.04\end{array}$ \\
\hline MDA-MB-35 & $>100$ & $>100$ & $\begin{array}{l}8.60 \\
7.48-10.10\end{array}$ & $\begin{array}{l}3.26 \\
2.90-3.98\end{array}$ & $>100$ & $>100$ & $>100$ & $>100$ & $>100$ & $\begin{array}{l}0.96 \\
0.68-1.32\end{array}$ \\
\hline Normal cells PBMC & $\begin{array}{l}30.50 \\
21.76-48.47\end{array}$ & $\begin{array}{l}8.30 \\
5.73-11.83\end{array}$ & $\mathrm{Nd}$ & $\begin{array}{l}36.05 \\
25.53-50.9\end{array}$ & $\mathrm{Nd}$ & $\mathrm{Nd}$ & $\mathrm{Nd}$ & $\mathrm{Nd}$ & $\mathrm{Nd}$ & $\begin{array}{l}1.66 \\
0.88-2.84\end{array}$ \\
\hline
\end{tabular}

Doxorubicin was used as positive control.

Data are presented as $\mathrm{IC}_{50}$ values and 95\% confidence interval from two independent experiments, performed two times. Nd: not determined.

lines. The mixture of isomers $\mathbf{5}$ and $\mathbf{6}$ was selective against all cancer cells tested (Table 1 ).

Addition of the acetyl group at the $\alpha$-methylene- $\gamma$-lactone group of 1, 2, 3, 4 giving 11, 12,13 and 14, respectively, resulted in decreased potency, which hinted at the importance of the $\alpha$ methylene- $\gamma$-lactone functionality.

\subsection{Hemolytic activity}

In order to verify whether the observed cytotoxic activity is related to membrane disruption, compounds $\mathbf{1}, \mathbf{9}$ and $\mathbf{1 0}$, described in our previous report, and 2-6 described herein were tested for their ability to induce lysis of mouse erythrocytes. The erythrocyte membrane is a dynamic structure that can dictate significant changes in its interaction with drugs [42]. The results revealed that these compounds did not show any hemolytic activity, suggesting that cytotoxic activity was not related to the lytic properties or membrane instability.

\section{Conclusion}

In conclusion, we described the first synthesis of the natural product parishin $\mathrm{A}$ and also preparation of another nine new $\alpha$-santonin derivatives. The cytotoxicity of all synthesized compounds was evaluated against four tumor cell lines, HL-60, SF295, HCT-8 and MDA-MB-435. Mechanisms by which bioactive lactones described herein, and in our previous report, exert their cytotoxic activities were also examined. Some of these derivatives (2-6) showed relatively high cytotoxicity against the tumor cells with $\mathrm{IC}_{50}$ values varied from 1.45 to $16.40 \mu \mathrm{M}$, although they are less potent than control reference. Sesquiterpene lactones evaluated in this study did not cause disruption of the cell membrane in mouse erythrocytes. Compound $\mathbf{2}$ is selective against cancer cells tested, except against MDA-MB-435, and demonstrate lower cytotoxic potency against normal cells represented by PBMC. Data suggest that PBMC are more sensitive to compound $\mathbf{3}$ than cancer cells. Mixture of isomers $\mathbf{5}$ and $\mathbf{6}$ is selective against all cancer cells tested (Table 1).

From the structure-activity relationships inferred, we may conclude that $\alpha$-methylene- $\gamma$-lactone functionality and endoperoxide unit play important roles for conferring cytotoxic activity to these sesquiterpene lactones. On the basis of the above results, the synthesis of other derivatives with good activity as well as more detailed studies of the mechanisms by which the most active compounds presented here exert their biological activities are ongoing in our laboratories.

\section{Material and methods}

\subsection{Synthesis}

Solvents were purified as described by Perrin and Armarego [43]. Commercial $\alpha$-santonin was purchased from Aldrich (Milwaukee, WI, USA) and utilized without further purification. Infrared spectra were recorded on a Perkin Elmer Paragon 1000 FTIR spectrophotometer, using potassium bromide (1\% w/w) disk scanning from 500 to $4000 \mathrm{~cm}^{-1}$. Flash column chromatography was performed using Crosfield Sorbil C60 silica gel (32-63 mm). Analytical thin layer chromatography analyses were conducted on precoated silica gel plates. Melting points were determined on an electrothermal digital apparatus model MQAPF-301 (Microquimica, Brazil), without correction. The ${ }^{1} \mathrm{H}$ and ${ }^{13} \mathrm{C}$ NMR spectra were recorded on VARIAN MERCURY 300 at 300 and $75 \mathrm{MHz}$, respectively, using $\mathrm{CDCl}_{3}$ as solvent and TMS as internal standard. Low resolution mass spectra were obtained on SHIMADZU GCMSQP5050A instrument by direct injection using the following temperature program: $40^{\circ} \mathrm{C} / \mathrm{min}$ until temperature reaches $60^{\circ} \mathrm{C}$; then $80{ }^{\circ} \mathrm{C} /$ min until temperature reaches $300{ }^{\circ} \mathrm{C}$; detector temp: $280{ }^{\circ} \mathrm{C}$. Values are reported as a ratio of mass to charge $(\mathrm{m} / \mathrm{z})$ in Daltons and relative intensities are quoted as a percentage value. HRMS data were recorded under different conditions of ionization on a Fisons Autospec-oaTof (resolution $=10.000$ FWHM): chemical ionization in $\mathrm{CI}^{+}$mode (compounds 2, 8, 11-14); chemical ionization in $\mathrm{CI}^{-}$mode (compound 3); electron impact $\left(\mathrm{EI}^{+}\right)$(compounds $\mathbf{5 , 6 , 9}$ ) and electrospray $\left(\mathrm{ESI}^{+}\right)$(compound 4). Optical rotation, $[\alpha]_{D}$ was measured using a $(\mathrm{B}+\mathrm{S})$ Bellingham + Stanley Ltd. manual polarimeter.

4.1.1. Synthesis of 11,13-dehydroisofotosantonic acid (2) and $10 \alpha-$ hydroxy-3-oxo-1,7 $\alpha \mathrm{H}, 6 \beta \mathrm{H}$-guaia-4,11-dien-6,12-olide (3)

A solution of compound $\mathbf{1}(500 \mathrm{mg}, 2.05 \mathrm{mmol})$ in a mixture of water $(80 \mathrm{~mL})$ and acetic acid $(80 \mathrm{~mL})$ in a pyrex vessel was degassed by a flow of nitrogen for $30 \mathrm{~min}$. The reaction mixture was then irradiated with a high pressure mercury lamp $(125 \mathrm{~W})$ for $21 \mathrm{~h}$. The solvent was evaporated under reduced pressure $\left(60{ }^{\circ} \mathrm{C}\right)$ to give a yellow oil which was purified by flash column chromatography (hexane-ethyl acetate $1: 2 \mathrm{v} / \mathrm{v})$ yielding 2 as a white solid $(0.258 \mathrm{~g}$, $0.98 \mathrm{mmol}$ ) in $48 \%$ yield and compound 3, also as a white solid (0.191 g, $0.73 \mathrm{mmol}$ ) in 36\% yield. Data for (2): $\mathrm{mp} 155.0-156.2{ }^{\circ} \mathrm{C}$; $[\alpha]^{20}{ }_{D}-21.1^{\circ}\left(\mathrm{c} 0.38, \mathrm{CH}_{2} \mathrm{Cl}_{2}\right)$; IR $(\mathrm{KBr}): v_{\max } 2600-3400,2987,2925$, 2867, 1772, 1703, 1247, $1005 \mathrm{~cm}^{-1}$; ${ }^{1} \mathrm{H}$ NMR (300 MHz, $\mathrm{CDCl}_{3}$ ): $\delta 1.36-1.52$ (dddd, $1 \mathrm{H}, J_{7 \mathrm{a}, 8 \mathrm{a}} \approx J_{7 \mathrm{a}, 6} \approx J_{7 \mathrm{a}, 7 \mathrm{e}}=12.6 \mathrm{~Hz}, J_{7 \mathrm{a}, 8 \mathrm{e}}=3.9 \mathrm{~Hz}$, H7a), 1.63 (s, 3H, H14), 1.77 (s, 3H, H15), 1.85-2.00 (m, 1H, H8a), $2.15-2.30$ (dddd, $1 \mathrm{H}, J_{7 \mathrm{e}, 7 \mathrm{a}}=12.6 \mathrm{~Hz}, J_{7 \mathrm{e}, 8 \mathrm{a}}=4.8 \mathrm{~Hz}, J_{7 \mathrm{e}, 6}=3.3 \mathrm{~Hz}$, 
$\left.J_{7 \mathrm{e}, 8 \mathrm{e}}=2.4 \mathrm{~Hz}, \mathrm{H} 7 \mathrm{e}\right), 2.60-2.75(\mathrm{~m}, 1 \mathrm{H}, \mathrm{H} 6), 2.80-2.90$ (ddd, $1 \mathrm{H}$, $\left.J_{8 \mathrm{e}, 8 \mathrm{a}}=14.1 \mathrm{~Hz}, J_{8 \mathrm{e}, 7 \mathrm{a}}=3.9 \mathrm{~Hz}, J_{8 \mathrm{e}, 7 \mathrm{e}}=2.4 \mathrm{~Hz}, \mathrm{H} 8 \mathrm{e}\right), 2.93-3.01$ (ddd, $1 \mathrm{H}, J_{2,2^{\prime}}=17.4 \mathrm{~Hz}, J_{2,3}=6.6 \mathrm{~Hz}, J_{2,5}=1.8 \mathrm{~Hz}, \mathrm{H} 2$ ), $2.94-3.10$ (ddd, $1 \mathrm{H}, J_{2^{\prime}, 2}=17.4 \mathrm{~Hz}, J_{2^{\prime}, 3}=7.8 \mathrm{~Hz}, J_{2^{\prime}, 5}=1.2 \mathrm{~Hz}, \mathrm{H} 2^{\prime}$ ), 4.10 (dddd, $1 \mathrm{H}$, $\left.J_{5,2}=1.8 \mathrm{~Hz}, J_{5,2^{\prime}}=1.2 \mathrm{~Hz}, J_{5,3}=1.8 \mathrm{~Hz}, J_{5,6}=11.2 \mathrm{~Hz}, \mathrm{H} 5\right), 5.40(\mathrm{~d}, 1 \mathrm{H}$, $J_{13,13^{\prime}}=3.3 \mathrm{~Hz}, \mathrm{H} 13$ ), 5.71 (ddd, $1 \mathrm{H}, J_{3,2}=7.8 \mathrm{~Hz}, J_{3,2^{\prime}}=6.6 \mathrm{~Hz}$, $\left.J_{3,5}=1.8 \mathrm{~Hz}, \mathrm{H} 3\right), 6.10\left(\mathrm{~d}, 1 \mathrm{H}, J_{13^{\prime}, 13}=3.3 \mathrm{~Hz}, \mathrm{H} 13^{\prime}\right) ;{ }^{13} \mathrm{C} \mathrm{NMR}(75 \mathrm{MHz}$, $\mathrm{CDCl}_{3}$ ): $\delta 20.25$ (C15), 22.43 (C14), 25.94 (C7), 30.21 (C8), 33.97 (C2), 51.68 (C6), 83.49 (C5), 111.14 (C3), 117.94 (C13), 127.37 (C9), 131.74 (C10), 139.72 (C11), 140.35 (C4), 170.36 (C12), 177.63 (C1); MS, m/z (\%): $262(18)\left[\mathrm{M}^{+}\right], 244$ (15), 229 (5), 216 (46), 202 (92), 189 (59), 173 (46), $159(13), 145$ (29), 131 (31), $117(22), 105$ (42), 91 (72), $77(49), 65$ (32); 53 (100); HRMS $\left(\mathrm{CI}^{+}\right) \mathrm{C}_{15} \mathrm{H}_{18} \mathrm{NaO}_{4}\left(\mathrm{MNa}^{+}\right)$requires 285.1097, found 285.1098 .

Data for (3): $\mathrm{mp} 177.0-178.1^{\circ} \mathrm{C} ;[\alpha]^{20} \mathrm{D}+72.8^{\circ}$ (c 1.07, MeOH); $[\alpha]^{20}{ }_{D}+62.5^{\circ}\left(\right.$ c $0.40, \mathrm{CH}_{2} \mathrm{Cl}_{2}$ ); IR $(\mathrm{KBr}): v_{\max } 3445,3062,2970$, 2930, 2863, 1768, 1699, 1641, 1257, 1142, 1115, $959 \mathrm{~cm}^{-1} ;{ }^{1} \mathrm{H}$ NMR (300 MHz, $\mathrm{CDCl}_{3}$ ): $\delta 0.97$ (s, 3H, H14), 1.40-1.60 (dddd, $1 \mathrm{H}$, $\left.J_{8^{\prime}, 7} \approx J_{8^{\prime}, 8} \approx J_{8^{\prime}, 9}=11.1 \mathrm{~Hz}, J_{8^{\prime}, 9^{\prime}}=3.6 \mathrm{~Hz}, \mathrm{H}^{\prime}\right), 1.80-1.91\left(\mathrm{~m}, 2 \mathrm{H}, \mathrm{H}^{\prime}\right.$ and $\mathrm{OH}), 1.92(\mathrm{~s}, 3 \mathrm{H}, \mathrm{H} 15), 2.08\left(\mathrm{dt}, 1 \mathrm{H}, J_{9,9^{\prime}}=13.5 \mathrm{~Hz}\right.$, $\left.J_{9,8^{\prime}}=J_{9,8}=3.6 \mathrm{~Hz}, \mathrm{H} 9\right), 2.20-2.35(\mathrm{~m}, 1 \mathrm{H}, \mathrm{H} 8), 2.54(\mathrm{dd}, 1 \mathrm{H}$, $\left.J_{2^{\prime}, 2}=20.1 \mathrm{~Hz}, J_{2^{\prime}, 1}=5.4 \mathrm{~Hz}, \mathrm{H} 2^{\prime}\right), 2.60\left(\mathrm{dd}, 1 \mathrm{H}, J_{2,2^{\prime}}=20.1 \mathrm{~Hz}\right.$, $\left.J_{2,1}=3.6 \mathrm{~Hz}, \mathrm{H} 2\right), 3.00\left(\mathrm{td}, 1 \mathrm{H}, J_{7,8^{\prime}}=J_{7,6}=11.1 \mathrm{~Hz}, J_{7,8}=1.5 \mathrm{~Hz}, \mathrm{H} 7\right)$, $3.20-3.30(\mathrm{~m}, 1 \mathrm{H}, \mathrm{H} 1), 4.80\left(\mathrm{~d}, 1 \mathrm{H}, J_{6,7}=11.1 \mathrm{~Hz}, \mathrm{H} 6\right), 5.60(\mathrm{~d}, 1 \mathrm{H}$, $\left.J_{13,13^{\prime}}=3.0 \mathrm{~Hz}, \mathrm{H} 13\right), 6.30\left(\mathrm{~d}, 1 \mathrm{H}, J_{13^{\prime}, 13}=3.0 \mathrm{~Hz}, \mathrm{H} 13^{\prime}\right) ;{ }^{13} \mathrm{C} \mathrm{NMR}$ (75 MHz, $\mathrm{CDCl}_{3}$ ): $\delta 9.73$ (C15), 21.52 (C14), 25.21 (C8), 37.47 (C2), 44.78 (C7), 45.08 (C9), 50.76 (C1), 74.66 (C10), 82.14 (C6), 121.03 (C13), 137.93 (C4), 143.12 (C11), 161.22 (C5), 169.18 (C12), 207.94 (C3); MS, m/z (\%): 262 (100) [ $\left.\mathrm{M}^{+\cdot}\right], 244$ (31), 229 (10), 219 (49), 204 (47), 191 (66), 174 (60), 173 (60), 159 (46), 145 (61), 131 (51), 117 (47), 110 (36), 91 (73), 77 (52), 67 (64), 53 (99); HRMS ( $\mathrm{CI}^{-}$) $\mathrm{C}_{15} \mathrm{H}_{17} \mathrm{O}_{4}$ $(\mathrm{M}-\mathrm{H})^{-}$requires 261.1132, found 261.1135 .

\subsubsection{Photochemical synthesis of 11,13-dehydromazdasantonin (4)}

A solution of 1 (500 mg, $2.00 \mathrm{mmol}$ ) in anhydrous acetonitrile $(250 \mathrm{~mL})$ in a quartz tube was degassed by a flow of nitrogen for $30 \mathrm{~min}$. The reaction mixture was then irradiated under four low pressure mercury lamps $(4 \times 15 \mathrm{~W})$ for $16 \mathrm{~h}$. The solvent was evaporated under reduced pressure $\left(40{ }^{\circ} \mathrm{C}\right)$ to give a yellow oil (500 mg, $2.00 \mathrm{mmol}$ ) in $100 \%$ yield. $[\alpha]^{20}{ }_{\mathrm{D}}+80.0^{\circ}$ (c $0.30, \mathrm{CH}_{2} \mathrm{Cl}_{2}$ ); IR (KBr): $v_{\max } 2971,2934,2875,1782,1661,1626,1027$, $981,713 \mathrm{~cm}^{-1} ; .{ }^{1} \mathrm{H}$ NMR (300 MHz, $\left.\mathrm{CDCl}_{3}\right): \delta 1.26(\mathrm{~s}, 6 \mathrm{H}, \mathrm{H} 14$ and $\mathrm{H} 15), \quad 1.68-1.82 \quad(\mathrm{~m}, 1 \mathrm{H}, \mathrm{H} 8 \mathrm{e}), 2.30-2.40$ (dddd, $1 \mathrm{H}$, $\left.J_{8 \mathrm{a}, 8 \mathrm{e}} \cong J_{8 \mathrm{a}, 9 \mathrm{a}} \cong J_{8 \mathrm{a}, 9 \mathrm{e}} \cong J_{6,7}=10.8, J_{8 \mathrm{a}, 7}=3.3, \mathrm{H} 8 \mathrm{a}\right), 2.53-2.61(\mathrm{~m}$, $2 \mathrm{H}, \mathrm{H} 9 \mathrm{a}, \mathrm{H} 9 \mathrm{e}$ ), $2.68-2.70$ (ddd, $1 \mathrm{H}, \mathrm{J}_{7,8 \mathrm{e}}=12.3, J_{7,6}=10.8, J_{7,8 \mathrm{a}}=3.3$,

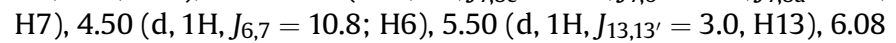
$\left(\mathrm{d}, 1 \mathrm{H}, J_{3,4}=9.9, \mathrm{H} 3\right), 6.18\left(\mathrm{~d}, 1 \mathrm{H}, J_{13^{\prime}, 13}=3.0, \mathrm{H} 13^{\prime}\right), 7.22(\mathrm{~d}, 1 \mathrm{H}$, $\left.J_{4,3}=9.9, \mathrm{H} 4\right) ;{ }^{13} \mathrm{C} \mathrm{NMR}\left(75 \mathrm{MHz}, \mathrm{CDCl}_{3}\right): \delta 21.18$ (C8), 24.88 (C14), 25.43 (C15), 25.94 (C9), 46.17 (C7), 50.28 (C1), 79.64 (C6), 118.84 (C13), 123.68 (C3), 125.72 (C5), 138.12 (C4), 138.88 (C11), 152.28 (C10), 170.57 (C12), 205.77 (C2); MS, m/z (\%): 244 (99) [M $\left.{ }^{+\cdot}\right]: 229$ (36), 215 (42), 201 (76), 187 (42), 145 (32), 131 (17), 115 (29), 91 (71), 77 (52), 65 (52), 53 (95), 39 (100); HRMS (ESI ${ }^{+}$) $\mathrm{C}_{15} \mathrm{H}_{17} \mathrm{O}_{3}\left(\mathrm{MH}^{+}\right)$ requires 245.1178 , found 245.1172 .

\subsubsection{Synthesis of mixture of isomers (5) and (6)}

A solution of compound $4(450 \mathrm{mg}, 1.84 \mathrm{mmol})$ in a mixture of anhydrous acetonitrile $(250 \mathrm{~mL})$ and rose bengal $(15 \mathrm{mg})$ in a pyrex vessel was bubbled by a flow of oxygen for $30 \mathrm{~min}$. The reaction mixture was then irradiated with a high pressure mercury lamp $(250 \mathrm{~W})$ for $5 \mathrm{~h}$. The solvent was evaporated under reduced pressure $\left(60^{\circ} \mathrm{C}\right)$ to give a yellow oil which was purified by flash column chromatography (hexane-ethyl acetate $3: 2 \mathrm{v} / \mathrm{v}$ ) yielding the mixture of isomers 5 and $\mathbf{6}$ as a white solid ( $150 \mathrm{mg}, 0.54 \mathrm{mmol})$ at a ratio of $1: 1.4$, in $29 \%$ yield. Mp $160.1-163.5{ }^{\circ} \mathrm{C} ;[\alpha]^{20}{ }_{D}-11.5^{\circ}$ (c
0.80, $\mathrm{CH}_{2} \mathrm{Cl}_{2}$ ); IR (KBr): $v_{\max } 3062,2973,2939,2878,1784,1741$, 1673, 1469, 1385, 1251, 1129, 1044, $977 \mathrm{~cm}^{-1}$; ${ }^{1} \mathrm{H}$ NMR $(300 \mathrm{MHz}$, $\mathrm{CDCl}_{3}$ ): $\delta 1.12(\mathrm{~s}, 3 \mathrm{H}, \mathrm{H} 15), 1.16$ (s, 3H, H15'), 1.29 (s, 3H, H14), 1.32 (s, 3H, H14'), 1.75-2.41 (m, 8H, H8a, H8e, H8a', H8e', H9a, H9e, H9a', $\mathrm{H}^{\prime} \mathrm{e}^{\prime}$ ), 2.63-2.75 (m, 1H. H7'), 2.96-3.09 (m, 1H. H7), 4.49 (dd, 1H, $\left.J_{6,7}=12.0, J_{6,4}=2.1, \mathrm{H} 6\right), 4.64\left(\mathrm{dd}, 1 \mathrm{H}, J_{6^{\prime}, 7^{\prime}}=12.6, J_{6^{\prime}, 4^{\prime}}=2.7, \mathrm{H}^{\prime}\right)$, $4.65\left(\mathrm{~d}, 1 \mathrm{H}, J_{3,4}=6.6 ; \mathrm{H} 3\right), 4.72\left(\mathrm{~d}, 1 \mathrm{H}, J_{3^{\prime}, 4^{\prime}}=6.6, \mathrm{H}^{\prime}\right), 5.52(\mathrm{~d}, 1 \mathrm{H}$, $\left.J_{13,13^{\prime}}=3.0, \mathrm{H} 13\right), 5.54\left(\mathrm{~d}, 1 \mathrm{H}, J_{13^{\prime \prime}, 13^{\prime \prime \prime}}=3.0, \mathrm{H} 13^{\prime \prime}\right), 6.21(\mathrm{~d}, 1 \mathrm{H}$, $\left.J_{13^{\prime}, 13}=3.0, \mathrm{H} 13^{\prime}\right), 6.24\left(\mathrm{~d}, 1 \mathrm{H}, J_{13^{\prime \prime \prime}, 13^{\prime \prime}}=3.0, \mathrm{H} 13^{\prime \prime \prime}\right), 6.57(\mathrm{dd}, 1 \mathrm{H}$, $\left.J_{4,3}=6.6, J_{4,6}=2.1, \mathrm{H} 4\right), 6.68\left(\mathrm{dd}, 1 \mathrm{H}, J_{4^{\prime}, 3^{\prime}}=6.6, J_{4^{\prime}, 6^{\prime}}=2.7, \mathrm{H} 4^{\prime}\right) ;{ }^{13} \mathrm{C}$ NMR (75 MHz, CDCl 3 ): $\delta$ 19.45-46.37 (C15, C14, C7, C8, C9, C1, C15', $\left.\mathrm{C} 14^{\prime}, \mathrm{C}^{\prime}, \mathrm{C} 8^{\prime}, \mathrm{C} 9^{\prime}, \mathrm{C} 1^{\prime}\right), 77.26-86.59\left(\mathrm{C} 3, \mathrm{C} 6, \mathrm{C} 10, \mathrm{C}^{\prime}, \mathrm{C}^{\prime}, \mathrm{C} 10^{\prime}\right)$, 115.55-149.72 (C4, C5, C11, C13, C4', C5', C11', C13'), $169.48\left(\mathrm{C} 12^{\prime}\right)$, 169.52 (C12), $204.67\left(\mathrm{C}^{\prime}\right), 204.84(\mathrm{C} 2)$; MS, $m / z(\%): 276(0.3)\left[\mathrm{M}^{+\cdot}\right]$, 247 (1), 244 (1), 233 (6), 178 (6), 149 (13), 133 (4), 121 (10), 95 (10), 91 (16), 70 (100), 53 (38); HRMS $\left(\mathrm{EI}^{+}\right) \mathrm{C}_{15} \mathrm{H}_{16} \mathrm{O}_{5}\left(\mathrm{M}^{+}\right)$requires 276.0998, found 276.0973 .

\subsubsection{Synthesis of phenylselenyl-lumisantonin (8)}

To a mixture of anhydrous diisopropylamine $(1.60 \mathrm{~mL}$, $11.00 \mathrm{mmol})$ and anhydrous THF $(8.00 \mathrm{~mL})$ in a two necked round bottomed flask under nitrogen atmosphere at $-78{ }^{\circ} \mathrm{C}$, was added n-BuLi ( $8.80 \mathrm{~mL}, 10.32 \mathrm{mmol})$. The mixture was stirred for $30 \mathrm{~min}$ and lumisantonin $(2.50 \mathrm{~g}, 12.2 \mathrm{mmol})$ in anhydrous THF $(30 \mathrm{~mL})$ was added. Phenyl selenium chloride $(2.15 \mathrm{~g}, 11.00 \mathrm{mmol})$ in anhydrous THF $(20 \mathrm{~mL})$ was added to the reaction mixture after $30 \mathrm{~min}$ and stirred for a further $20 \mathrm{~min}$ at $-78{ }^{\circ} \mathrm{C}$. Distilled water $\left(30 \mathrm{~mL}\right.$ ) was added to the mixture at $25^{\circ} \mathrm{C}$; the resulting mixture was transferred to a separatory funnel, and extracted with DCM $(3 \times 30 \mathrm{~mL})$. The combined organic layers was washed with brine $(30 \mathrm{~mL})$, dried with anhydrous magnesium sulphate, filtered, and concentrated under reduced pressure. The residue was purified by flash column chromatography eluted with hexane/ethyl acetate $(3: 2 \mathrm{v} / \mathrm{v})$, yielding compound $(\mathbf{8})$ as a white solid (1.94 g, $4.82 \mathrm{mmol}$ ) in $49 \%$ yield. Mp $198.9-199.7^{\circ} \mathrm{C} ;[\alpha]^{20} \mathrm{D}+15.5^{\circ}$ (c 0.84 , $\mathrm{CH}_{2} \mathrm{Cl}_{2}$ ); IR (KBr): $v_{\max } 3068,2952,2875,1770,1701,1570,1475$, 1440, 1031, 999, 752, $693 \mathrm{~cm}^{-1}$; ${ }^{1} \mathrm{H}$ NMR (300 MHz, $\left.\mathrm{CDCl}_{3}\right): \delta 1.12(\mathrm{~s}$, $3 \mathrm{H}, \mathrm{H} 14), 1.25$ (s, 3H, H13), 1.59 (s, 3H, H15), 1.40-1.55 (m, 1H, H9e), 1.80-2.00 (m, 4H, H7, H8e, H8a, H9a), 4.3 (d, 1H, J6,7 = 10.8, H6), $6.00\left(\mathrm{~d}, 1 \mathrm{H}, J_{3,4}=5.7, \mathrm{H} 3\right), 7.30\left(\mathrm{t}, 1 \mathrm{H}, J_{3^{\prime}, 4^{\prime}} \cong J_{3^{\prime}, 2^{\prime}}=8.1, \mathrm{H} 3^{\prime}\right.$ e H5 $5^{\prime}$, $7.40\left(\mathrm{tt}, 2 \mathrm{H}, J_{4^{\prime}, 3^{\prime}}=8.1, J_{4^{\prime}, 2^{\prime}}=1.5, \mathrm{H} 4^{\prime}\right), 7.60\left(\mathrm{~d}, 1 \mathrm{H}, J_{4,3}=5.7, \mathrm{H} 4\right), 7.62$ (dd, $\left.2 \mathrm{H}, J_{2^{\prime}, 4^{\prime}}=1.5, J_{2^{\prime}, 3^{\prime}}=8.1, \mathrm{H}^{\prime} \mathrm{e} \mathrm{H6} 6^{\prime}\right) ;{ }^{13} \mathrm{C} \mathrm{NMR}\left(75 \mathrm{MHz}, \mathrm{CDCl}_{3}\right)$ : $\delta 7.75$ (C13), 17.28 (C14), 20.59 (C9), 22.83 (C15), 29.96 (C8), 40.58 (C5), 43.06 (C1), 49.44 (C10), 50.21 (C11), 53.45 (C7), 75.73 (C6), $124.19\left(\mathrm{C1}^{\prime}\right), 129.45\left(\mathrm{C3}^{\prime} \mathrm{e} \mathrm{C} 5^{\prime}\right), 130.16\left(\mathrm{C}^{\prime}\right), 131.72(\mathrm{C} 3), 138.43\left(\mathrm{C2}^{\prime} \mathrm{e}\right.$ C6'), 157.86 (C4), 176.38 (C12), 206.80 (C2); MS, m/z (\%): 402 (9) $\left[\mathrm{M}^{+} \cdot\right.$ ], 244 (93), 216 (100), 201 (17), 188 (34), 173 (18), 157(18), 105 (30), 91 (46), 77 (49), 65 (23), 55 (44), 41 (53). HRMS $\left(\mathrm{CI}^{+}\right)$ $\mathrm{C}_{21} \mathrm{H}_{22} \mathrm{NaO}_{3} \mathrm{Se}\left(\mathrm{MNa}^{+}\right)$requires 425.0627 , found 425.0622 .

\subsubsection{Synthesis of 11,13-dehydrolumisantonin (9)}

To a solution of compound $8(0.450 \mathrm{~g}, 1.13 \mathrm{mmol})$ in anhydrous THF $(6 \mathrm{~mL})$, and acetic acid $(0.20 \mathrm{~mL})$ in a two necked round bottomed flask at $0{ }^{\circ} \mathrm{C}$ was added hydrogen peroxide $30 \%(0.80 \mathrm{~mL})$. The mixture was stirred for $1 \mathrm{~h}$ at $0{ }^{\circ} \mathrm{C}$, and the reaction was quenched with aqueous sodium bicarbonate $\left(2 \mathrm{~mol} \mathrm{~L}^{-1}, 10 \mathrm{~mL}\right)$. The mixture was transferred into a separatory funnel, and extracted with diethyl ether $(3 \times 30 \mathrm{~mL})$. The combined organic layers was washed with brine $(30 \mathrm{~mL})$, dried with anhydrous magnesium sulphate, filtered, and concentrated under reduced pressure. The residue was purified by flash column chromatography eluted with hexane/ethyl acetate $(2: 1 \mathrm{v} / \mathrm{v})$ to afford compound $\mathbf{9}$ as a yellow solid (0.200 g. $0.82 \mathrm{mmol})$ in $73 \%$ yield. $\mathrm{Mp}=153.1-154.2{ }^{\circ} \mathrm{C} ;[\alpha]^{20} \mathrm{D}$ $-91.3^{\circ}$ (c $1.22, \mathrm{CH}_{2} \mathrm{Cl}_{2}$ ); IR ( $\mathrm{KBr}$ ): $v_{\max } 2929,2876,1776,1698,1568$, 1381, 1258, 1134, 1039, 1073, 976, 838, $689 \mathrm{~cm}^{-1} ;{ }^{1} \mathrm{H}$ NMR 
(300 MHz, $\mathrm{CDCl}_{3}$ ): $\delta 1.17$ (s, 3H, H14), 1.25 (s, 3H, H15), 1.30-1.40 (dddd, $\left.1 \mathrm{H}, J_{8 \mathrm{a}, 8 \mathrm{e}} \cong J_{8 \mathrm{a}, 9 \mathrm{a}} \cong J_{8 \mathrm{a}, 7} \cong J_{6,7}=11.2, J_{8 \mathrm{a}, 9 \mathrm{e}}=2.6, \mathrm{H} 8 \mathrm{a}\right)$, 1.88-2.00 ( $\mathrm{m}, 2 \mathrm{H}, \mathrm{H} 9 \mathrm{a}, \mathrm{H} 9 \mathrm{e}$ ), 2.14-2.21 ( $\mathrm{m}, 1 \mathrm{H}, \mathrm{H} 8 \mathrm{e}$ ), 2.56-2.65 ( $\mathrm{m}$, $1 \mathrm{H}, \mathrm{H} 7), 3.82$ (d, $\left.1 \mathrm{H}, J_{6,7}=11.2, \mathrm{H} 6\right), 5.50$ (d, $1 \mathrm{H}, J_{13,13^{\prime}}=3.1, \mathrm{H} 13$ ), $6.06\left(\mathrm{~d}, 1 \mathrm{H}, J_{3,4}=5.8, \mathrm{H} 3\right), 6.19\left(\mathrm{~d}, 1 \mathrm{H}, J_{13^{\prime}, 13}=3.1, \mathrm{H} 13^{\prime}\right), 7.65(\mathrm{~d}, 1 \mathrm{H}$, $\left.J_{4,3}=5.8, \mathrm{H} 4\right) ;{ }^{13} \mathrm{C}$ NMR $\left(75 \mathrm{MHz}, \mathrm{CDCl}_{3}\right): \delta 7.50$ (C15), 16.92 (C14), 20.99 (C8), 28.62 (C9), 40.48 (C5), 43.23 (C1), 45.49 (C7), 50.13 (C10), 77.55 (C6), 119.24 (C13), 131.49 (C3), 138.36 (C11), 157.10 (C4), 170.00 (C12), 206.40 (C2); MS, $m / z$ (\%): 244 (30) [ $\left.\mathrm{M}^{+\cdot}\right], 229$ (11), 215 (10), 201 (15), 173 (19), 145 (17), 105 (20), 84 (100), 77(32), 53 (72), 51 (98). HRMS $\left(\mathrm{EI}^{+}\right) \mathrm{C}_{15} \mathrm{H}_{16} \mathrm{O}_{3}\left(\mathrm{M}^{+}\right)$requires 244.1099, found 244.1093.

\subsubsection{Typical procedure for the synthesis of compounds 11-14}

To a pyrex vessel, equipped with a solution of $\mathrm{Ni}$ (II) and Co (II) as a filter, were added the starting material $(\mathbf{1}-\mathbf{3}, \mathbf{9} ; 0.35 \mathrm{mmol})$ and $45 \mathrm{~mL}$ of distilled acetaldehyde. The reaction mixture was degassed by a flow of nitrogen for $30 \mathrm{~min}$ and then irradiated with a high pressure mercury lamp ( $125 \mathrm{~W}$ ) for $22 \mathrm{~h}$. The filter solution was prepared by mixing $\mathrm{NiSO}_{4} \cdot 6 \mathrm{H}_{2} \mathrm{O}(46 \mathrm{~g})$ and $\mathrm{CoSO}_{4} \cdot 7 \mathrm{H}_{2} \mathrm{O}(14 \mathrm{~g})$ and $100 \mathrm{~mL}$ of water. At the end of the reaction, the mixture was concentrated under reduced pressure with the addition of small amounts of cyclohexane. The reaction mixture was purified by flash column chromatography eluted with an appropriated mixture of solvents.

\subsubsection{3-Oxo-7 $\alpha \mathrm{H}, 6,11 \beta \mathrm{H}-13$-acetyl-eudesma-1,4-dien-6,12-olide} (11). White solid; Yield: 45\%; mp $165.3-166.2{ }^{\circ} \mathrm{C}$; $[\alpha]^{20}{ }_{\mathrm{D}}+55.5^{\circ}$ (c $0.18, \mathrm{CH}_{2} \mathrm{Cl}_{2}$ ); IR (KBr): $v_{\max } 3002,2931,2872,1781,1717,1663$, $1635,1613,1458,1372,1152,1036 \mathrm{~cm}^{-1} ;{ }^{1} \mathrm{H} \mathrm{NMR}\left(300 \mathrm{MHz}, \mathrm{CDCl}_{3}\right)$ : $\delta 1.32$ (s, 3H, H16), 1.38-1.50 (m, 1H, H8a), 1.70-2.00 (m, 4H, H7, H8e, H9e, H9a), 2.12 (s, 3H, H17), 2.22 (s, 3H, H15), 2.60 (dd, 1H, $\left.J_{13,13^{\prime}}=18.3, J_{13,11}=7.5, \mathrm{H} 13\right), 2.90\left(\mathrm{ddd}, 1 \mathrm{H}, J_{11,7}=12.0, J_{11,13}=7.5\right.$, $\left.J_{11,13^{\prime}}=3.9, \mathrm{H} 11\right), 3.10\left(\mathrm{dd}, 1 \mathrm{H}, J_{13^{\prime}, 13}=18.3, J_{13^{\prime}, 11}=3.9, \mathrm{H} 13^{\prime}\right), 4.8(\mathrm{~d}$, $\left.1 \mathrm{H}, J_{6,7}=11.1, \mathrm{H} 6\right), 6.20\left(\mathrm{~d}, 1 \mathrm{H}, J_{2.1}=9.6, \mathrm{H} 2\right), 6.60\left(\mathrm{~d}, 1 \mathrm{H}, J_{1,2}=9.6\right.$, $\mathrm{H} 1$ ); ${ }^{13} \mathrm{C}$ NMR (75 MHz, $\left.\mathrm{CDCl}_{3}\right): \delta 11.12$ (C17), 23.78 (C9), 25.29 (C16), 30.37 (C15), 38.05 (C8), 41.49 (C10), 41.51 (C11), 42.19 (C13), 52.43 (C7), 81.88 (C6), 126.12 (C2), 129.10 (C4), 150.93 (C5), 155.17 (C1), 176.75 (C12), 186.53 (C3), 205.40 (C14); MS, $m / z$ (\%): $288(0.01)$ [ $\mathrm{M}^{+}$.], 245 (0.13), 230 (9), 187 (6), 173 (8), 135 (29), 91 (18), 77 (13), 65 (10), 55 (17), 53 (9), 43 (100), 41 (16); HRMS $\left(\mathrm{Cl}^{+}\right) \mathrm{C}_{17} \mathrm{H}_{20} \mathrm{NaO}_{4}$ $\left(\mathrm{MNa}^{+}\right)$requires 311.1254, found 311.1256.

4.1.6.2. 13-Acetylisophotosantonic acid (12). Yellow oil; Yield: 36\%; $[\alpha]^{20}{ }_{D}+33.2^{\circ}$ (c $0.18, \mathrm{CH}_{2} \mathrm{Cl}_{2}$ ); IR (KBr): $v_{\max } 2600-3400,2923$, 2857, 1778, 1716, 1160, $1007 \mathrm{~cm}^{-1}$; ${ }^{1} \mathrm{H}$ NMR (300 MHz, $\left.\mathrm{CDCl}_{3}\right)$ : $\delta 1.36-1.52$ (dddd, $\left.1 \mathrm{H}, J_{7 \mathrm{a}, 8 \mathrm{a}} \cong J_{7 \mathrm{a}, 6} \cong J_{7 \mathrm{a}, 7 \mathrm{e}}=12.6, J_{7 \mathrm{a}, 8 \mathrm{e}}=3.9, \mathrm{H7a}\right)$, 1.63 (s, 3H, H16), 1.77 (s, 3H, H17), 1.80-2.00 (m, 3H, H6, H7e, H8a), 2.22 (s, 3H, H15), 2.00 (dd, $\left.1 \mathrm{H}, J_{13,13^{\prime}}=18.3, J_{13,11}=7.2, \mathrm{H} 13\right), 2.80$ $\left(\mathrm{ddd}, 1 \mathrm{H}, J_{8 \mathrm{e}, 8 \mathrm{a}}=13.2, J_{8 \mathrm{e}, 7 \mathrm{a}}=3.9, J_{8 \mathrm{e}, 7 \mathrm{e}}=1.8, \mathrm{H} 8 \mathrm{e}\right), 2.89-3.01(\mathrm{~m}$, $\left.3 \mathrm{H}, \mathrm{H} 2, \mathrm{H} 2^{\prime}, \mathrm{H} 11\right), 3.02-3.10\left(\mathrm{dd}, 1 \mathrm{H}, J_{13^{\prime}, 13}=18.3, J_{13^{\prime}, 11}=4.5, \mathrm{H} 13^{\prime}\right.$ ), $4.20(\mathrm{~m}, 1 \mathrm{H}, \mathrm{H} 5), 5.60\left(\mathrm{dt}, 1 \mathrm{H}, J_{3,2} \cong J_{3,2^{\prime}}=7.1, J_{3,5}=1.8, \mathrm{H} 3\right) ;{ }^{13} \mathrm{C}$ NMR (75 MHz, $\mathrm{CDCl}_{3}$ ): $\delta 20.17$ (C17), 22.36 (C16), 28.10 (C7), 30.43 (C15), 30.56 (C8), 33.91 (C2), 42.37 (C13), 42.77 (C11), 53.30 (C6), 83.81 (C5), 110.85 (C3), 127.52 (C9), 131.29 (C10), 140.16 (C4), 177.64 (C1, C12), 205.74 (C14); MS, $m / z$ (\%): 306 (11) [ $\left.\mathrm{M}^{+\cdot}\right], 288$ (8), 263 (5), 248 (63), 230 (67), 212 (25), 191 (54), 175 (40), 163 (28), 145 (42), 131 (59), 119 (26), 105 (41), 91 (71), 77 (41), 55 (100); HRMS $\left(\mathrm{CI}^{+}\right)$ $\mathrm{C}_{17} \mathrm{H}_{22} \mathrm{NaO}_{5}\left(\mathrm{MNa}^{+}\right)$requires 329.1359 , found 329.1362 .

4.1.6.3. $10 \alpha$-Hydroxy-3-oxo-1,7 $\alpha H, 6,11 \beta H$-13-acetyl-guaia-4-en6,12-olide (13). Yellow oil; Yield: $45 \%$; $[\alpha]^{20}{ }_{D}+18.2^{\circ}$ (c 0.44 , $\mathrm{CH}_{2} \mathrm{Cl}_{2}$ ); IR (KBr): $v_{\max } 3441,3062,2923,2853,1769,1697,1643$, 1454, 1165, $989 \mathrm{~cm}^{-1} ;{ }^{1} \mathrm{H}$ NMR (300 MHz, $\left.\mathrm{CDCl}_{3}\right): \delta 0.94(\mathrm{~s}, 3 \mathrm{H}$, $\mathrm{H} 16), 1.35-1.60$ ( $\left.\mathrm{m}, 1 \mathrm{H}, \mathrm{H}^{\prime}\right), 1.65-1.80$ ( $\left.\mathrm{m}, 2 \mathrm{H}, \mathrm{H} 9^{\prime}, \mathrm{OH}\right) ; 1.89$ (s, 3H,
H17), 1.93-2.10 ( $\mathrm{m}, 2 \mathrm{H}, \mathrm{H} 8, \mathrm{H} 9$ ), 2.24 (s, 3H, H15), 2.31-2.43 (dddd, $\left.1 \mathrm{H}, J_{7,11} \cong J_{7,8^{\prime}} \cong J_{7,6}=11.1, J_{7,8}=1.2 . \mathrm{H} 7\right), 2.46-2.54(\mathrm{dd}, 1 \mathrm{H}$, $\left.J_{2^{\prime}, 2}=19.5, J_{2^{\prime}, 1}=5.4, \mathrm{H} 2^{\prime}\right), 2.46-2.64\left(\mathrm{dd}, 1 \mathrm{H}, J_{2,2^{\prime}}=19.5, J_{2,1}=2.7\right.$, $\mathrm{H} 2), 2.70\left(\mathrm{dd}, 1 \mathrm{H}, J_{13,13^{\prime}}=18.0, J_{13,11}=5.4, \mathrm{H} 13\right) ; 2.80(\mathrm{ddd}, 1 \mathrm{H}$, $\left.J_{11,7}=12.0, J_{11,13}=5.4, J_{11,13^{\prime}}=4.5, \mathrm{H} 11\right), 3.00\left(\mathrm{dd}, 1 \mathrm{H}, J_{13^{\prime}, 13}=18.0\right.$, $\left.J_{13^{\prime}, 11}=4.5, \mathrm{H}_{13}^{\prime}\right), 3.20(\mathrm{~m}, 1 \mathrm{H}, \mathrm{H} 1), 4.85\left(\mathrm{~d}, 1 \mathrm{H}, J_{6,7}=11.1, \mathrm{H} 6\right) ;{ }^{13} \mathrm{C}$ NMR (75 MHz, CDCl $): \delta 9.69$ (C17), 21.49 (C16), 26.05 (C8), 30.50 (C15), 37.36 (C2), 41.21 (C13), 45.41 (C11), 46.57 (C9), 50.65 (C7) 53.66 (C1), 74.60 (C10), 82.03 (C6), 143.38 (C4), 161.29 (C5), 176.32 (C12), 205.34 (C14), 207.99 (C3); MS, $m / z(\%): 306$ (6) $\left[\mathrm{M}^{+\cdot}\right], 288(2)$, 270 (3), 245 (5), 217 (3), 203 (4), 191 (6), 175 (4), 149 (8), 133 (10), 105 (7), 91 (8), 77 (6), 55 (9), 43 (100); HRMS ( $\left.\mathrm{Cl}^{+}\right) \mathrm{C}_{17} \mathrm{H}_{22} \mathrm{NaO}_{5}$ $\left(\mathrm{MNa}^{+}\right)$requires 329.1359, found 329.1362.

4.1.6.4. 13-Acetyllumisantonin (14). White solid; Yield: $52 \%$; $\mathrm{mp}$ $170.1-171.4^{\circ} \mathrm{C} ;[\alpha]^{20}{ }_{\mathrm{D}}+36.3^{\circ}\left(\mathrm{c} 0.22, \mathrm{CH}_{2} \mathrm{Cl}_{2}\right)$; IR $(\mathrm{KBr}): v_{\max } 3070$, 2931, 2872, 1782, 1717, 1700, 1570, 1159, 1000; ${ }^{1} \mathrm{H}$ NMR $(300 \mathrm{MHz}$ $\left.\mathrm{CDCl}_{3}\right): \delta 1.11$ (s, 3H, H16), $1.24(\mathrm{~s}, 3 \mathrm{H}, \mathrm{H} 17) ; 1.25-1.35$ (m, 1H, H8a), 1.70-2.00 (m, 4H, H7, H8e, H9e, H9a), 2.22 (s, 3H, H15), 2.60 (dd, $\left.1 \mathrm{H}, J_{13,13^{\prime}}=18.3, J_{13,11}=7.2 ; \mathrm{H} 13\right), 2.80\left(\mathrm{ddd}, 1 \mathrm{H}, J_{11,7}=12.3\right.$, $\left.J_{11,13}=7.2, J_{11,13^{\prime}}=3.9, \mathrm{H} 11\right), 3.04\left(\mathrm{dd}, 1 \mathrm{H}, J_{13^{\prime}, 13}=18.3, J_{13^{\prime}, 11}=3.9\right.$, $\left.\mathrm{H}^{\prime} 3^{\prime}\right), 3.86$ (d, $\left.1 \mathrm{H}, J_{6,7}=10.8, \mathrm{H} 6\right), 6.00\left(\mathrm{~d}, 1 \mathrm{H}, J_{3,4}=5.7, \mathrm{H} 3\right), 7.60$ $\left(\mathrm{d}, 1 \mathrm{H}, J_{4,3}=5.7, \mathrm{H} 4\right) ;{ }^{13} \mathrm{C}$ NMR $\left(75 \mathrm{MHz}, \mathrm{CDCl}_{3}\right): \delta 7.65(\mathrm{C} 17), 17.38$ (C16), 23.14 (C8), 29.78 (C9), 30.38 (C15), 40.67 (C5), 41.93 (C11), 42.04 (C13), 42.90 (C1), 47.88 (C7), 50.20 (C10), 78.27 (C6), 131.68 (C3), 157.74 (C4), 177.64 (C12), 205.38 (C14), 206.76 (C2); MS, m/z (\%): $288(0.6)\left[\mathrm{M}^{+\cdot}\right], 270$ (10), 245 (3), 227 (10), 191 (59), 173 (48), 157 (15), 145 (50), 131 (18), 117 (12), 107 (100), 91 (47), 77 (23), 55 (45); HRMS $\left(\mathrm{Cl}^{+}\right) \mathrm{C}_{17} \mathrm{H}_{20} \mathrm{NaO}_{4}\left(\mathrm{MNa}^{+}\right)$requires 311.1254 , found 311.1255

\subsection{MTT assay}

The cytotoxicity of the synthesized compounds was evaluated against HL-60 (leukemia), SF-295 (central nervous system), HCT-8 (colon), and MDA-MB-435 (melanoma) human cancer cell lines, all obtained from the National Cancer Institute, Bethesda, MD, USA. The cells were grown in RPMI-1640 medium supplemented with $10 \%$ fetal bovine serum, $2 \mathrm{mM}$ glutamine, $100 \mu \mathrm{g} / \mathrm{mL}$ streptomycin and $100 \mathrm{U} / \mathrm{mL}$ penicillin, and incubated at $37{ }^{\circ} \mathrm{C}$ with a $5 \% \mathrm{CO}_{2}$ atmosphere.

The tumor cell growth was quantified by the ability of living cells to reduce the yellow dye 3-(4,5-dimethyl-2-thiazolyl)-2,5diphenyl-2H-tetrazolium bromide (MTT) to a purple formazan product [44]. For all experiments, the cells were seeded in 96-well plates (105 cells/well for adherent cells or $0.5 \times 10^{5}$ cells/well for suspended cells in $100 \mu \mathrm{L}$ of medium). After $24 \mathrm{~h}$, the compounds $(0.09-25 \mu \mathrm{g} / \mathrm{mL})$, dissolved in DMSO, were added to each well (using the HTS - high-throughput screening - Biomek $3000-$ Beckman Coulter, Inc. Fullerton, California, USA) and incubated for 72 h. Doxorubicin (Sigma Aldrich Co., St Louis, MO, USA) was used as a positive control. At the end of the incubation, the plates were centrifuged and the medium was replaced by fresh medium $(150 \mu \mathrm{L})$ containing $0.5 \mathrm{mg} / \mathrm{mL}$ MTT. After $3 \mathrm{~h}$, the formazan product was dissolved in $150 \mu \mathrm{L}$ DMSO and the absorbance was measured using a multiplate reader (DTX 880 Multimode Detector, Beckman Coulter, Inc. Fullerton, Califórnia, USA). The drug effect was quantified as the percentage of control absorbance of reduced dye at $595 \mathrm{~nm}$.

\subsection{Hemolytic assay}

The test was performed in 96-well plates following the method described by Costa-Lotufo et al. [45]. Each well received $100 \mu \mathrm{L}$ of $0.85 \% \mathrm{NaCl}$ solution containing $10 \mathrm{mM} \mathrm{CaCl}_{2}$. The first well was the 
negative control that contained only the vehicle (distilled water or DMSO 10\%), and, in the second well, $100 \mu \mathrm{L}$ of the test substance that was diluted to half was added. The compounds were tested at concentrations ranging from 10 to $200 \mu \mathrm{g} / \mathrm{mL}$. The serial dilution continued until the eleventh well. The last well received $20 \mu \mathrm{L}$ of $0.1 \%$ Triton X-100 (in $0.85 \%$ saline) to obtain $100 \%$ hemolysis (positive control). Then, each well received $100 \mu \mathrm{L}$ of a $2 \%$ suspension of mouse erythrocytes in $0.85 \%$ saline containing $10 \mathrm{mM} \mathrm{CaCl}$. After incubation at room temperature for $30 \mathrm{~min}$ and centrifugation, the supernadant was removed and the liberated hemoglobin was measured spectroscopically as absorbance at $540 \mathrm{~nm}$.

\subsection{Normal cell assay}

The cytotoxic effects of the synthesized compounds were evaluated against PBMC (Peripheral Blood Mononuclear Cells) from healthy donors, using Alamar Blue assay. Heparinized blood (from healthy, non-smoker donors who had not taken any drug at least 15 days prior to sampling) was collected and PBMC were isolated by a standard method of density-gradient centrifugation over FicollHypaque. PBMC were washed and re-suspended at a concentration of $3 \times 10^{5}$ cells $\mathrm{mL}^{-1}$ in RPMI-1640 medium supplemented with $20 \%$ fetal bovine serum, $2 \mathrm{mM}$ glutamine, $100 \mathrm{U} \mathrm{mL}^{-1}$ penicillin, $100 \mathrm{mg} \mathrm{mL}^{-1}$ streptomycin at $37{ }^{\circ} \mathrm{C}$ with $5 \% \mathrm{CO}_{2}$. Phytohemagglutinin $(2 \%)$ was added at the beginning of culture. After $24 \mathrm{~h}$ of culture, cells were treated with the test compounds.

In order to investigate selectivity of the compounds towards a normal proliferating cell, the Alamar Blue assay was performed with PBMC after $72 \mathrm{~h}$ drug exposure [46]. Briefly, PBMC were plated in 96 -well plates $\left(3 \times 10^{5}\right.$ cells/well in $100 \mu \mathrm{L}$ of medium). After $24 \mathrm{~h}$, the compounds $\left(0.09-25 \mu \mathrm{g} \mathrm{mL}^{-1}\right)$ dissolved in DMSO were added to each well (using the HTS - high-throughput screening biomek 3000-Beckman Coulter, Inc. Fullerton, California, USA) and incubated for $72 \mathrm{~h}$. Doxorubicin was used as positive control. Twenty-four hours before the end of the incubation, $10 \mu \mathrm{L}$ of stock solution $\left(0.312 \mathrm{mg} \mathrm{mL}^{-1}\right)$ of the Alamar Blue (resazurin - Sigma Aldrich Co. - St. Louis, MO/USA) were added to each well. The absorbance was measured using a multiplate reader (DTX 880 Multimode Detector, Beckman Coulter, Inc. Fullerton, California, USA). The drug effect was quantified as the percentage of control absorbance at $570 \mathrm{~nm}$ and $595 \mathrm{~nm}$.

\subsection{Statistical analysis}

The $\mathrm{IC}_{50}$ values and their $95 \%$ confidence intervals $(95 \% \mathrm{CI})$ were obtained by nonlinear regression using the Prism Program (GraphPad Software Inc., San Diego, CA).

\section{Acknowledgements}

We are grateful to the following Brazilian agencies: Conselho Nacional de Desenvolvimento Científico e Tecnológico (CNPq) for research fellowships (AJD, CRAM, LCAB), Fundação de Amparo à Pesquisa de Minas Gerais (FAPEMIG), Coordenação de Aperfeiçoamento de Pessoal de Nível Superior (CAPES) and FINEP for financial support.

\section{Appendix. Supplementary data}

Supplementary data related to this article can be found online at doi: 10.1016/j.ejmech.2010.10.003

\section{References}

[1] J.D. Connolly, R.A. Hill, Dictionary of Terpenoids, vol. 1, Chapman and Hall, London, 1991.

[2] S.P. Hehner, M. Heinrich, P.M. Bork, M. Vogt, F. Ratter, V. Lehmann, K. SchulzeOsthoff, W. Droge, M.L. Schmitz, J. Biol. Chem. 273 (1998) 1288-1297.

[3] L.C.A. Barbosa, J. Mann, J. Chem. Soc. Perkin. I (1990) 177-178.

[4] S. Zhang, Y.K. Wan, Ch. N. Ong, H.M. Shen, Curr. Med. Chem. 5 (2005) 239-249.

[5] L.C.A. Barbosa, A.J. Demuner, E.E.L. Borges, J. Mann, J. Braz. Chem. Soc. 8 (1997) 19-27.

[6] L.C.A. Barbosa, C.R.A. Maltha, E.E.L. Borges, Quím. Nova 25 (2002) 203-208.

[7] F.A. Macías, J.C.G. Galindo, D. Castellano, R.F. Velasco, J. Agric. Food Chem. 48 (2000) 5288-5296

[8] F.A. Macías, A. Fernandez, R.M. Varela, J.M.G. Molinillo, A. Torres, P.L.C.A. Alves, J. Nat. Prod. 69 (2006) 795-800.

[9] L.C.A. Barbosa, A.V. Costa, D. Piló-Veloso, J.L.C. Lopes, M.G. Hernandez-Terrones, B. King-Diaz, B. Lotina-Hennsen, Z. Naturforsch. 59 (2004) 803-805.

[10] L.M. Polo, C.M. Castro, M.C. Cruzado, C.J.G. Collino, F.D. Cuello-Carrión, D.R. Ciocca, O.S. Giordano, M. Ferrari, L.A. López, Eur. J. Pharmacol. 556 (2007) 19-26.

[11] S.M. Kupchan, M.A. Eakin, A.M. Thomas, J. Med. Chem. 14 (1971) 1147-1152.

[12] K.H. Lee, Y.S. Wu, I.H. Hall, J. Med. Chem. 20 (1977) 911-914.

[13] Y. Nakagawa, M. Iinuma, N. Matsuura, K. Yi, M. Naoi, T. Nakayama, Y. Nozawa, Y. Akao, J. Pharmacol. Sci. 97 (2005) 242-252.

[14] M. Rozalski, U. Krajewska, M. Panczyk, M. Mirowski, B. Rozalska, T. Wasek, T. Janecki, Eur. J. Med. Chem. 42 (2007) 248-255.

[15] F.A. Macías, J.C.G. Galindo, G.M. Massanet, Phytochemistry 31 (1992) 1969-1977.

[16] F.F.P. Arantes, L.C.A. Barbosa, E.S. Alvarenga, A.J. Demuner, D.P. Bezerra, J.R.O. Ferreira, L.V. Costa-Lotufo, C. Pessoa, M.O. Moraes, Eur. J. Med. Chem. 44 (2009) 3739-3745.

[17] I.H. Hall, K.H. Lee, E.C. Mar, C.O. Starnes, J. Med. Chem. 20 (1977) 333-336.

[18] J.M. Woynarowski, J. Konopa, Mol. Pharmacol. 19 (1981) 97-102.

[19] Y.S. Kim, J.S. Kim, S.-H. Park, S.-U. Choi, Ch.O. Lee, S.-K. Kim, Y.-K. Kim, S.H. Kim, S.Y. Ryu, Planta Med. 69 (2003) 375-377.

[20] V.M. Dirsch, H. Stuppner, A.M. Vollmar, Cancer Res. 61 (2001) 5817-5823.

[21] A. Rivero, J. Quintana, J.L. Eiroa, M. Lopez, J. Triana, J. Bermejo, F. Estevez, Eur. J. Pharmacol. 482 (2003) 77-84.

[22] J.H. Choi, J. Ha, J.H. Park, J.Y. Lee, Y.S. Lee, H.J. Park, J.W. Choi, Y. Masuda, K. Nakoia, K.T. Lee, J. Cancer Res. 93 (2002) 1327-1333.

[23] S.H. Lee, M.Y. Lee, H.M. Kang, D.C. Han, K.H. Son, D.C. Yang, N.D. Sang, C.W. Lee, H.M. Kin, B.M. Kwon, Bioorg. Med. Chem. 11 (2003) 4545-4549.

[24] S.O. Duke, K.C. Vaughn, E.M. Croom Jr., H.N. Elsohly, Weed Sci. 35 (1987) 499-505.

[25] P.K. Chen, G.R. Leather, J. Chem. Ecol. 16 (1990) 1867-1876.

[26] L.C.A. Barbosa, J. Mann, J. Chem. Soc. Perkin. I (1992) 337-342.

[27] R.R. Teixeira, L.C. Barbosa, C.R. Maltha, M.E. Rocha, D.P. Bezerra, L.V. CostaLotufo, C. Pessoa, M.O. Moraes, Molecules 12 (2007) 1101-1116.

[28] C. Pessoa, E.R. Silveira, T.L. Lemos, L.A. Wetmore, M.O. Moraes, A. Leyva, Phytother. Res. 14 (2000) 187-191.

[29] L.V. Costa-Lotufo, E.R. Silveira, M.C. Barros, M.A. Lima, M.E. De Moraes, M.O. De Moraes, C. Pessoa, Planta Med. 70 (2004) 180-182.

[30] D.P. Bezerra, C. Pessoa, M.O. Moraes, N.M. Alencar, R.O. Mesquita, M.W. Lima, A.P. Alves, O.D. Pessoa, J.H. Chaves, E.R. Silveira, L.V. Costa-Lotufo, J. Appl. Toxicol. 28 (2008) 599-607.

[31] Y.B. Kiran, C.D. Reddy, D. Gunasekar, C.S. Reddy, A. Leon, L.C.A. Barbosa, Eur. J. Med. Chem. 43 (2008) 885-892.

[32] M.A. Irwin, PhD Thesis, UCLA, 1971.

[33] C. Zdero, F. Bohlmann, M. Muller, Phytochemistry 26 (1987) 2763-2775.

[34] S. Zhang, J. Wang, H. Xue, Q. Deng, F. Xing, M. Ando, J. Nat. Prod. 65 (2002) 1927-1929.

[35] S. Zhang, M. Zhao, L. Bai, T. Hasegawa, J. Wang, L. Wang, H. Xue, Q. Deng, F. Xing, Y. Bai, J. Sakay, J. Bai, R. Koyanagi, Y. Tsukumo, T. Kataoka, K. Nagai, K. Hirose, M. Ando, J. Nat. Prod. 69 (2006) 1425-1428.

[36] O.L. Chapman, L.F. Englert, J. Am. Chem. Soc. (1963) 3028-3029.

[37] D.H.R. Barton, P. de Mayo, M. Shafiq, J. Chem. Soc. 140 (1958) 140-145

[38] F.A. Macías, V.M.I. Viñolo, F.R. Fronczek, G.M. Massanet, J.M.G. Molinillo, Tetrahedron 62 (2006) 7747-7755.

[39] M. Wang, B. Cornett, J. Nettles, D. Liotta, J. Zinder, J. Org. Chem. 65 (2000) 1059-1068.

[40] E.S. Alvarenga, L.C.A. Barbosa, W.A. Saliba, F.F.P. Arantes, A.J. Demuner, Quim. Nova 32 (2009) 401-406.

[41] J.A. Marco, J.F. Sanz, E. Falcó, Tetrahedron 46 (1990) 7941-7950.

[42] H. Aki, M. Yamoto, Biochem. Pharmacol. 41 (1991) 133-138.

[43] D.D. Perrin, W.L.F. Armarego, third edition. Pergamon Press, Oxford, 1994

[44] T. Mosmann, J. Immunol. Methods 16 (1983) 55-63.

[45] L.V. Costa-Lotufo, G.M.A. Cunha, J.B. Fontenele, H.V.N. Júnior, F.C.M. Sousa, E.R. Silveira, N.A.P. Nogueira, M.O. Moraes, G.S.B. Viana, Phytother Res. 17 (2003) 155-159.

[46] S.A. Ahmed, R.M. Gogal, J.E. Walsh, J. Immunol. Methods 170 (1994) 211-224. 